\title{
EVALUATION OF SERUM CONCENTRATIONS OF VASCULAR ENDOTHELIAL GROWTH FACTOR (VEGF) IN BREAST CANCER PATIENTS
}

\author{
Diana Hodorowicz-Zaniewska ${ }^{1}$, Wojciech KibiL ${ }^{1}$, AgnieszKa MaŁeK², Joanna SzPor 3 , \\ Jan Kulig ${ }^{1}$, Krystyna SZTefKO ${ }^{2}$
}

\author{
${ }^{1}$ First Chair of General, Oncological, and Gastrointestinal Surgery, Jagiellonian University Medical College, Krakow \\ 2Department of Clinical Biochemistry at Polish-American Institute of Pediatrics, Jagiellonian University Medical \\ College, Krakow \\ 3Chair of Pathomorphology, Jagiellonian University Medical College, Krakow
}

\begin{abstract}
The aim of the study was to assess the value of vascular endothelial growth factor (VEGF) measurements in breast cancer patients with respect to recognized clinicopathological prognostic factors.

The study was conducted in 87 women with histologically confirmed breast cancer who underwent surgical treatment and 37 healthy women. Vascular endothelial growth factor concentration levels in the blood samples of patients were correlated with the size of the primary tumor, lymph nodes in the armpit, cancer stage, histological type, grading, multifocality, status of estrogen and progesterone receptors and HER-2 protein expression.

Statistical analysis did not show any correlation between concentrations of VEGF and any of the selected parameters. The comparison of VEGF concentrations showed a slightly raised level of VEGF in women with the disease as opposed to the healthy subjects but the differences were not statistically significant $(\mathrm{p}=0.472)$. Similar results were obtained for marker CEA ( $\mathrm{p}=0.09$ ), while the level of Ca 15-3 in both groups differed significantly $(\mathrm{p}<0.001)$ reaching higher values in the patients with diagnosed breast cancer.

Vascular endothelial growth factor concentrations in breast cancer patients do not correlate with recognized clinicopathological prognostic factors and CEA and Ca 15-3 markers, which does not preclude the potential role of VEGF as an independent prognostic factor.
\end{abstract}

Key words: vascular endothelial growth factor (VEGF), breast cancer, prognostic factors.

\section{Introduction}

Breast cancer is the most common malignant neoplasm in women and leading cause of cancer-related death in this group. The etiology of breast cancer remains largely unknown. Risk factors associated with the disease include female gender, advanced age, menopause, breast cancer in the opposite breast, pos- itive family history of breast cancer, BRCA1 and BRCA2 mutation, high socioeconomic status, childlessness, alcohol consumption and obesity. Despite enormous progress that has taken place in diagnosing breast cancer, treatment results remain unsatisfactory. Therefore, it seems necessary to seek new, independent prognostic and predictive factors as well as optimal treatment methods. 
In 1971, Folkman noticed that the growth of neoplasm is strictly linked to the process of angiogenesis, i.e. the formation of new capillary vessels within the tumor [1]. Progress of such pathological angiogenesis enables local progress in the growth of the neoplasm and contributes to the formation of distant metastasis [2]. A tumor without its own vessels, fed via diffusion, may achieve a diameter of only 2-3 mm. Further stages of its growth require production of substances that promote the creation of a new network of capillary vessels that will provide nutrition.

Angiogenesis, also called neovascularization, may occur in physiological conditions (wound healing) or in a pathological state (inflammation, tumor). A number of complex reactions lead to the formation of new blood vessels from a preexisting vascular network. A signal to start such process may be oxygen or nutrient shortages in tissue, as well as mutation of some suppressor genes or oncogenes. A direct effect of the above processes is tumor-induced angiogenesis [3].

Neoangiogenesis involves the activity of cytokines, enzymes, growth factors and adhesion molecules secreted by both tumor cells and stroma cells (fibroblasts, neutrophils, macrophages, lymphocytes). They include fibroblast growth factor (FGF), transforming growth factor (TGF), interleukin-8 and prostaglandins [4]. At present, the vascular endothelial growth factor (VEGF) is considered to be the most important regulator in this process. Identified by Ferrara in 1989 [5], it is also called the vascular permeability factor (VPF) or vasculotropin. Binding with the vascular endothelium receptors, VEGF induces the angiogenic phenotype related to constant stimulation of angiogenesis processes $[6,7]$. Vascular endothelial growth factor stimulates the proliferation of endothelial cells in arteries, veins and lymphatic vessels and affects their migration. By disintegrating cell binding proteins, so called cadherins, it loosens intracellular connections. New vessels are different from normal ones. They are twisted, widened or denerved, have numerous arteriovascular fistulas, and are hyperpermeable tortuous and irregularly shaped. All of the above facilitates cancer cells passage to the blood circulation system and is conducive to distant metastasis [8].

A high expression of VEGF has been found in many kinds of tumors and in body fluids, as for example cancer of breast, large intestine, prostate, kidneys, and bladder.

The reports on the role of VEGF in breast cancer patients are not conclusive. Some research suggests that a high level of VEGF may affect the biological malignancy of tumor, it may promote invasive growth and metastases to regional lymph nodes and distant organs [9, 10]. Some authors raise VEGF's unfavorable prognostic value, showing a correlation between a high level of VEGF and shorter survival rate [11-13]. Others indicate a relationship between a high concentration of this factor and poorer response to a systemic chemo- and immunotherapy [14-16].

\section{Objective of the study}

The aim of the study was to assess the value of VEGF measurements in breast cancer patients with respect to recognized, clinicopathological prognostic factors. Separating the group of patients with particularly poor prognosis, even before surgical treatment, may affect the change of the therapeutical strategy, which not only has a cognitive value but is also of a clinical importance.

\section{Material and methods}

The study was conducted in 87 women with histologically confirmed breast cancer who underwent either radical surgery or breast conserving treatment in 2007-2009 at the Clinic of General, Oncological and Gastroenterological Surgery of the University Hospital in Krakow.

Patients disqualified from the study were those:

- after breast cancer operations conducted outside the Clinic,

- after chemo- or radiotherapy administered as induction treatment outside the Clinic,

- with metastatic cancer (M1) and cancer recurrence after primary treatment,

- with coexisting - in the past or in the present - malignant tumors in other organs,

- with diabetes, heart failure, lung diseases or ongoing infection.

Blood samples were collected from the patients with pre-invasive breast cancer, stage I, IIA and IIB invasive cancers immediately before surgery, and from the patients with locally/regionally advanced (stage III) breast cancer before initial hormone treatment or chemotherapy. Serum VEGF levels were measured by immunoenzymatic method using ELISA kit. Samples for the blood clotting test were centrifugated and stored at $-20^{\circ} \mathrm{C}$. The measurements were done at the Department of Clinical Biochemistry of the Polish-American Institute of Pediatrics, Jagiellonian University Medical College. Additionally, concentrations of CEA and Ca 15-3 were tested. The control group consisted of 37 women subjected to screening tests at the Regional Outpatient Clinic of Breast Diseases at the Clinic of General, Oncological and Gastroenterological Surgery of the University Hospital in Cracow, in whom no pathologies were found by imaging tests.

All histopathological tests were performed in the Chair of Pathomorphology of the Jagiellonian University Medical College.

The results of histopathological tests were correlated with the VEGF concentration levels, to assess the size of the primary tumor, lymph nodes in the armpit, cancer stage according to the TNM classification, histo- 
logical type, grading, multifocality, status of estrogen and progesterone receptors and HER-2 protein expression. Breast operations were also evaluated in terms of radicality of surgery.

The associations between the VEGF concentration and selected parameters were analyzed using the Pearson's linear correlation coefficient and Mann-Whitney test. The results were shown in the tables. A probability value of $\leq 0.05$ was considered statistically significant. All statistical calculations were done using the STATISTICA 3 program.

\section{Results}

The study consisted of 87 women with breast cancer, aged 32-85 (mean age 58 years). Statistical analysis did not show any correlation between concentrations of VEGF and any of the selected parameters, i.e. clinical stage of cancer, size of the primary tumor, metastasis to regional lymph nodes, degree of histological malignancy, angioinvasion, type of neoplasm, number of cancer foci, histological type or the expression of estrogen receptors, progesterone receptors and HER-2 protein in tumor cells (Table I).

The comparison of VEGF concentrations in both groups showed a slightly raised level of VEGF in women with the disease as opposed to the healthy subjects but the differences were not statistically significant $(\mathrm{p}=$ $=0.472$ ). Similar results were obtained for marker CEA ( $p=0.09$ ), while the level of $\mathrm{Ca} \mathrm{15-3} \mathrm{in} \mathrm{both} \mathrm{groups}$ differed significantly $(\mathrm{p}<0.001)$ reaching clearly higher values in the patients with diagnosed breast cancer (Table II).

Statistical analysis of obtained results did not reveal correlations between concentrations of VEGF vs. Ca 15-3 (Fig. 1) and VEGF vs. CEA (Fig. 2).

\section{Discussion}

Identification of prognostic factors in cancer, also breast cancer, helps to predict the probable course of tumor growth, allows to select an optimal treatment, and consequently enables longer survival. The introduction of modern methods in pathomorphology, immunohistochemistry and molecular biology has contributed to discovering new prognostic factors. The most important group comprises those whose prognostic value for breast cancer has been fully documented. These include tumor size, condition of regional lymph nodes, cancer stage in accordance with the pTNM classification, histological type, grading, status of estrogen and progesterone receptors. Other factors that are tested in the clinical studies include proliferation markers (MIB1), HER2/c-erb, p53, occurrence of angioinvasion. There are also factors whose prognostic value has not yet been fully documented. These are VEGF, TGF- $\alpha$ or cathepsin D [17].
As mentioned in the introduction, angiogenesis is inevitable in the tumor growth and formation of locoregional and systemic metastases [18-20]. The role of VEGF in the angiogenesis is well recognized. A high expression of VEGF is connected in most cases with poor prognosis [21]. Learning in detail about the phenomena related to the formation of pathological vasculature within the tumor and blocking VEGF may therefore be an opportunity to stop tumor progression. Antiangiogenic therapy with the use of drugs inhibiting angiogenesis is now intensively researched. Despite promising preliminary results regarding bevacizumab - a monoclonal antibody that inhibits formation of new blood vessels [22], there is still no effective method to cure breast cancer [23].

The results of the studies analyzing correlations between serum concentrations of VEGF in breast cancer patients and the stage of cancer (pTNM), histological type, grading, status of estrogen and progesterone receptors, and HER2 protein expression are inconsistent. Some authors indicate the correlation between a high concentration of VEGF, tumor size, and metastasis to regional lymph nodes [24-26]. Significantly higher VEGF concentrations were found in the patients with metastatic cancer as compared with a group of patients with an advanced stage of local or regional cancer $[27,28]$. Our results are significantly different. No correlation was found between concentrations of VEGF and the patient's age, size of the primary tumor, metastasis to lymph nodes, cancer stage according to the TNM classification, grading, histological type as well as the number of cancer foci. Similar results were obtained by other authors. Granato, Gasparini, Toi, de Paola found no correlation between VEGF concentrations and tumor size or metastasis to regional lymph nodes [29-33] and no correlation was found in the study of Sanack between VEGF levels and cancer stage [34].

Among the prognostic factors in breast cancer are estrogen and progesterone receptors which are positive in $70-80 \%$ of tumors. Approximately $65-76 \%$ of cancers with a positive receptor status respond well to the hormone suppression treatment. The other prognostic factor is overexpression of human epidermal growth factor receptor 2 (HER-2) occurring in $25-40 \%$ of patients. Its incidence is usually connected with higher biological malignancy of the tumor and a more aggressive course of the disease. It negatively affects response to chemotherapy and hormone treatment, despite the presence of receptors of estrogen and progesterone on the surface of cancer cells [14-16]. Some studies indicate a correlation between lack of hormone receptors [35] and independently overexpression of HER-2 [36, 37] in women with high serum concentrations of VEGF [36, 37].

Approximately 10-15\% of all breast cancers are triple-negative tumors that do not show expression of es- 
Table I. VEGF concentrations depending on the tested histoclinical parameters

\begin{tabular}{|c|c|c|c|c|c|}
\hline \multirow[t]{2}{*}{ PARAMETER } & & \multirow[t]{2}{*}{ No. } & \multicolumn{2}{|c|}{ VEGF [PG/ML] } & \multirow[t]{2}{*}{$\mathbf{P}$} \\
\hline & & & MEAN & $\mathrm{SD}$ & \\
\hline \multirow[t]{2}{*}{ Age } & $<50$ years old & 15 & 485.25 & 331.66 & 0.090 \\
\hline & $\geq 50$ years old & 72 & 330.26 & 330.43 & \\
\hline \multirow[t]{6}{*}{ Histological type } & Ductal & 52 & 300.61 & 243.50 & 0.336 \\
\hline & Lobular & 22 & 270.86 & 248.98 & \\
\hline & Medullary & 6 & 313.95 & 200.09 & - \\
\hline & DCIS & 2 & 279.80 & 147.76 & - \\
\hline & Squamous cell & 2 & 955.85 & 209.37 & - \\
\hline & Mixed & 3 & 352.46 & 267.41 & - \\
\hline \multirow[t]{2}{*}{ Number of foci } & 1 & 61 & 317.46 & 263.44 & 0.299 \\
\hline & Multi-focal & 26 & 331.70 & 247.16 & \\
\hline \multirow[t]{3}{*}{ Grading } & 1 & 6 & 335.50 & 279.89 & 0.988 \\
\hline & 2 & 19 & 329.36 & 300.82 & \\
\hline & 3 & 30 & 322.82 & 253.07 & \\
\hline \multirow[t]{5}{*}{$\mathrm{pT}$} & IS & 2 & 197.95 & 58.90 & - \\
\hline & 1 & 52 & 277.77 & 209,77 & 0.439 \\
\hline & 2 & 26 & 346.13 & 285.50 & \\
\hline & 3 & 2 & 1019.40 & 27.44 & - \\
\hline & 4 & 2 & 242.75 & 213.62 & - \\
\hline \multirow[t]{4}{*}{$\mathrm{pN}$} & 0 & 53 & 306.96 & 245.95 & 0.788 \\
\hline & 1 & 12 & 222.60 & 137.30 & \\
\hline & 2 & 12 & 301.13 & 212.61 & \\
\hline & 3 & 10 & 442.89 & 391.02 & \\
\hline \multirow[t]{8}{*}{ Stage of cancer } & 0 & 3 & 279.80 & 147.76 & - \\
\hline & I & 34 & 275.01 & 216.64 & 0.394 \\
\hline & IIA & 26 & 328.17 & 262.17 & \\
\hline & IIB & 1 & 126.10 & & - \\
\hline & IIIA & 11 & 292.70 & 220.87 & - \\
\hline & IIIB & 2 & 242.75 & 213.62 & - \\
\hline & IIIC & 9 & 466.17 & 407.32 & - \\
\hline & IV & 1 & 233.40 & & - \\
\hline \multirow[t]{2}{*}{ Angioinvasion } & $\mathrm{N}$ & 80 & 295.22 & 235.67 & 0.251 \\
\hline & $\mathrm{T}$ & 7 & 480.63 & 384.51 & \\
\hline \multirow[t]{2}{*}{ E receptor expression } & Negative & 28 & 346.00 & 283.26 & 0.576 \\
\hline & Positive & 59 & 293.13 & 237.68 & \\
\hline \multirow[t]{2}{*}{ PG receptor expression } & Negative & 38 & 335.29 & 274.78 & 0.599 \\
\hline & Positive & 49 & 290.64 & 235.40 & \\
\hline \multirow[t]{3}{*}{ HER 2 protein expression } & $0,1+$ & 56 & 328.76 & 264.95 & 0.502 \\
\hline & $2+$ & 10 & 228.90 & 137.00 & \\
\hline & $3+$ & 21 & 299.18 & 262.51 & \\
\hline \multirow[t]{2}{*}{ Radicality of resection } & R0 & 80 & 344.24 & 330.65 & 0.180 \\
\hline & $\mathrm{R} 1$ & 7 & 330.65 & 386.22 & \\
\hline
\end{tabular}

trogen, progesterone receptors and HER-2 protein. Such configuration suggests limited options for adjuvant treatment and, which could be observed in recent years, it is related to poorer prognosis. Some authors reported significantly higher concentrations of VEGF in triple negative cancers $[16,38]$. 
Table II. Comparison of VEGF, CEA, and Ca 15-3 levels in breast cancer patients and in the controls

\begin{tabular}{|c|c|c|c|c|c|c|c|c|c|c|}
\hline \multirow[t]{2}{*}{ GROUP } & \multirow[t]{2}{*}{ No. } & \multicolumn{3}{|c|}{ VEGF [PG/ML] } & \multicolumn{3}{|c|}{ CEA [NG/ML] } & \multicolumn{3}{|c|}{ CA $15-3$ [U/ML] } \\
\hline & & MEAN & SD & $P$ & MEAN & SD & $P$ & MEAN & $\mathrm{SD}$ & $P$ \\
\hline $\begin{array}{l}\text { Study } \\
\text { group }\end{array}$ & 87 & 310.14 & 252.80 & 0.472 & 2.28 & 1.50 & 0.090 & 12.87 & 7.19 & $<0.001$ \\
\hline Controls & 38 & 294.27 & 154.53 & & 2.18 & 1.06 & & 7.60 & 5.71 & \\
\hline
\end{tabular}

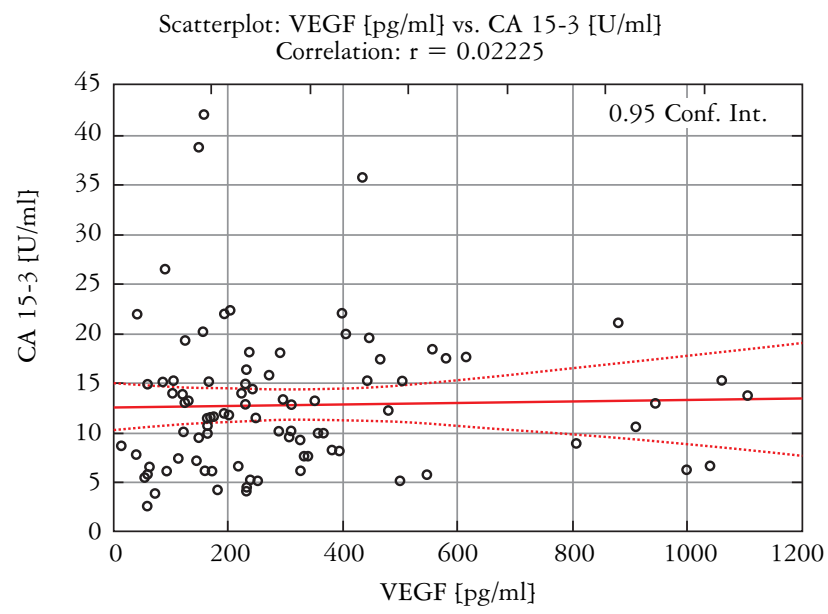

Fig. 1. Correlations between VEGF concentrations and Ca 15-3 level

Meanwhile, our own research has not confirmed the correlation between serum concentrations of VEGF and expression of estrogen, progesterone receptors and HER-2 in any of the possible configurations.

In view of our own observations and conflicting opinions reported in other studies, it seems that concentration measurements of VEGF may have a prognostic value in breast cancer patients. We have not included follow-up observations in the study, and therefore the role of VEGF as an independent prognostic factor in the analyzed group of patients cannot be excluded.

\section{Conclusions}

1. Vascular endothelial growth factor concentrations in breast cancer patients do not correlate with the clinical stage of neoplasm, the size of primary tumor, metastasis to regional lymph nodes, degree of histological malignancy, type of cancer, number of cancer foci, histological type and expression of estrogen receptors, progesterone receptors, and HER-2 protein in the tumor cells.

2. No correlation was found between VEGF concentrations in breast cancer patients and CEA and $\mathrm{Ca}$ 15-3 markers.

3. Lack of correlation between the recognized prognostic factors does not preclude a potential role of VEGF as an independent prognostic factor in breast cancer.

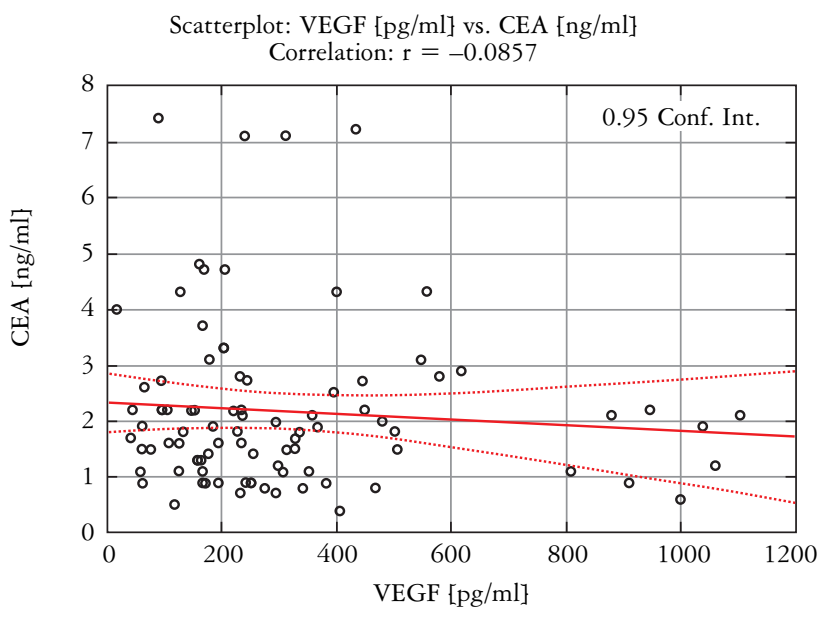

Fig. 2. Correlations between VEGF concentrations and CEA level

4. The role of VEGF as a prognostic factor in breast cancer and its applications in antiangiogenic therapy requires further clinical research.

The authors declare no conflict of interest.

\section{References}

1. Folkman J. Tumor angiogenesis: therapeutic implications. N Engl J Med 1971; 285: 1182-1186.

2. Schneider BP, Miller KD. Angiogenesis of breast cancer. Clin Oncol 2005; 23: 1782-1790.

3. Petruzzelli GJ. The biology of tumor invasion, angiogenesis and lymph node metastasis. ORL J Otorhinolaryngol Relat Spec 2000; 62: 178-185.

4. Eisma RJ, Spiro JD, Kreutzer DL. Role of angiogenic factors: coexpression of interleukin-8 and vascular endothelium growth factor in patients with head and neck squamous carcinoma. Laryngoscope 1999; 109: 687-693.

5. Ferrara N, Henzel WJ. Pituitary follicular cells secrete a novel heparyn-bind growth factor specific for vascular endothelial cells. Biochem Biophys Res Commun 1989; 161: 851-858.

6 . Ferrara N. VEGF and the quest for tumour angiogenesis factors. Nat Rev Cancer 2002; 2: 795-803.

7. Gerber HP, Ferrara N. The role of VEGF in normal and neoplastic hematopoesis. J Mol Med (Berl) 2003; 81: 20-31.

8. Nagy JA, Morgan ES, Herzberg KT, et al. Pathogenesis of ascites tumor growth: angiogenesis, vascular remodeling and stroma formation in the peritoneal lining. Cancer Res 1995; 55 : 376-385. 
9. Weidner N, Folkman J, Pozza F, et al. Tumor angiogenesis: a new significant and independent prognostic indicator in early stage breast carcinoma. J Natl Cancer Inst 1992; 84: 1875-1887.

10. Seo Y, Baba H, Fukuda T, et al. High expression of vascular endothelial growth factor is associated with liver metastasis and poor prognosis in ductal pancreatic adenocarcinoma. Cancer 2000; 88: 2239-2245.

11. Ghosh S, Sullivan CA, Zerkowski MP, et al. High levels of vascular endothelial growth factor and its receptors (VEGFR-1, VEGFR-2, neuropilin-1) are associated with worse outcome in breast cancer. Hum Pathol 2008; 39: 1835-1843.

12. Hu Z, Fan C, Livasy C, et al. A compact VEGF signature associated with distant metastases and poor outcomes. BMC Med 2009; 7: 9 .

13. Linderholm B, Grankvist K, Wilking N, et al. Correlation of vascular endothelial growth factor content with recurrences, survival and first relapse site in primary node-positive breast carcinoma after adjuvant treatment. J Clin Oncol 2000; 18 1423-1431.

14. Foekens JA, Peters HA, Grebenchtchikov N, et al. High tumor levels of vascular endothelial growth factor predict poor response to systemic therapy in advanced breast cancer. Cancer Res 2001; 61: $5407-5414$

15. Gasparini G. Prognostic value of vascular endothelial growth factor in breast cancer. Oncologist 2000; 5 Suppl 1: 37-44.

16. Taha FM, Zeeneldin AA, Helal AM, et al. Prognostic value of serum vascular endothelial growth factor in Egyptian females with metastatic triple negative breast cancer. Clin Biochem 2009; 42: 1420-1426.

17. Henson DE, Fielding LP, Grignon DJ, et al. College of American Pathologists Conference XXVI on clinical relevance of prognostic markers in solid tumors. Summary. Members of the Cancer Committee. Arch Pathol Lab Med 1995; 119: 1109-1112.

18. Khosravi Shahi P, Soria Lovelle A, Pérez Manga G. Tumoral angiogenesis and breast cancer. Clin Transl Oncol 2009; 11: 138142 .

19. Bergers G, Benjamin LE. Tumorigenesis and the angiogenic switch. Nat Rev Cancer 2003; 3: 401-410.

20. Folkman J. What is the evidence that tumors are angiogenesis dependent? J Natl Cancer Inst 1990; 82: 4-6.

21. Dvorak HF. Vascular permeability factor/vascular endothelial growth factor: a critical cytokine in tumor angiogenesis and a potential target for diagnosis and therapy. J Clin Oncol 2002; 20: 4368-4380.

22. Ranieri G, Patruno R, Ruggieri E, et al. Vascular endothelial growth factor (VEGF) as a target of bevacizumab in cancer: from the biology to the clinic. Curr Med Chem 2006; 16: 1845-1857.

23. Rhee J, Hoff PM. Angiogenesis inhibitors in the treatment of cancer. Expert Opin Pharmacother 2005; 6: 1701-1711.

24. Litwiniuk M, Łojko A, Thielemann A, Kopczyński Z. Zależność stężenia naczyniowo-śródbłonkowego czynnika wzrostu (VEGF) od wybranych parametrów klinicznych w niezaawansowanym raku piersi. Wspolczesna Onkol 2007; 11: 300-304.

25. Heer K, Kumar H, Read JR, et al. Serum vascular endothelial growth factor in breast cancer: its relation with cancer type and estrogen receptor status. Clin Cancer Res 2001; 7: 3491-3494.

26. Yamamoto Y, Toi M, Kondo S, et al. Concentrations of vascular endothelial growth factor in the sera of normal controls and cancer patients. Clin Cancer Res 1996; 2: 821-826.

27. Salven P, Perhoniemi V, Tykkä H, et al. Serum VEGF levels in women with a benign breast tumor or breast cancer. Breast Cancer Res Treat 1999; 53: 161-166.

28. Kraft A, Weindel K, Ochs A, et al. Vascular endothelial growth factor in the sera and effusions of patients with malignant and non-malignant disease. Cancer 1999; 85: 178-187.

29. Granato AM, Nanni O, Falcini F, et al. Basic fibroblast growth factor and vascular endothelial growth factor serum levels in breast cancer patients and healthy women: useful as diagnostic tools? Breast Cancer Res 2004; 6: R38-45.

30. Gasparini G, Toi M, Gion M, et al. Prognostic significance of vascular endothelial growth factor in node-negative breast carcinoma. J Natl Cancer Inst 1997; 89: 139-147.

31. Gasparini G, Toi M, Miceli R, et al. Clinical relevance of vascular endothelial growth factor and thymidine phosphorylase in patients with node-positive breast cancer treated with either adjuvant chemotherapy or hormone therapy. Cancer J Sci Am 1999; 5: 101-111.

32. Toi M, Bando H, Ogawa T, et al. Significance of vascular endothelial growth factor (VEGF)/soluble VEGF receptor-1 relationship in breast cancer. Int J Cancer 2002; 98: 14-18.

33. De Paola F, Granato AM, Scarpi E, et al. Vascular endothelial growth factor and prognosis in patients with node-negative breast cancer. Int J Cancer 2002; 98: 228-233.

34. Sancak B, Coskun U, Gunel N, et al. No association between serum levels of insulin-like growth factor-1, vascular endothelial growth factor, prolactin and clinicopathological characteristics of breast carcinoma after surgery. Inter Med J 2004; 3 : $310-$ 315.

35. Fuckar D, Dekanić A, Stifter S, et al. VEGF expression is associated with negative estrogen receptor status in patients with breast cancer. Int J Surg Pathol 2006; 14: 49-55.

36. Sledge GW Jr. VEGF-targeting therapy for breast cancer. J Mammary Gland Biol Neoplasia 2005; 10: 319-323.

37. Konecny GE, Meng YG, Untch M, et al. Association between HER-2/neu and vascular endothelial growth factor expression predicts clinical outcome in primary breast cancer patients. Clin Cancer Res 2004; 10: 1706-1716.

38. Linderholm BK, Hellborg H, Johansson U, et al. Significantly higher levels of vascular endothelial growth factor (VEGF) and shorter survival times for patients with primary operable triplenegative breast cancer. Ann Oncol 2009; 20: 1639-1646.

\section{Address for correspondence}

\section{Wojciech Kibil}

First Chair of General, Oncological, and Gastrointestinal Surgery Jagiellonian University Medical College

40 Kopernika St

31-501 Krakow

tel. +48600667739

fax +48124248007

e-mail: wkibil@op.pl 